\title{
Biowaiver Studies of Atenolol Tablets (100mg) - An Alternative to In Vivo Bioequivalence Studies
}

Shahnaz Usman*, Aftab Alam, Nadda Nadeem, Rameesha Khawar and Zainab Intesar

Department of Pharmaceutics, RAK College of Pharmaceutical Sciences, RAK Medical and Health Sciences University, Ras AI Khaimah, UAE

\begin{abstract}
The aim of present study was to compare the quality of atenolol tablets and examine the possibility of biowaiver study for approval of generic drugs without additional in vivo bioequivalence study. Atenolol, a cardio selective $\beta$-blocker, could be clearly classified into BCS Class III and may be evaluated under biowaiver conditions. Due to the importance of atenolol and availability of different generics in a community basis, four products available in Ras Al Khaimah were analyzed. Four brands of atenolol $100 \mathrm{mg}$ tablets have been evaluated using some quality control parameters, such as weight variation, hardness, content assay, disintegration and dissolution test. In vitro dissolution testing can be used in some cases not only to determine the quality of the pharmaceutical products but also to demonstrate bioequivalence to the generic product. Similarity factor $\left(f_{2}\right)$ and Difference Factor $\left(f_{1}\right)$ were used to assess bioequivalency among four products. The FDA recommended dissolution medium for atenolol is $0.1 \mathrm{~N} \mathrm{HCl}$ but it shows a good releasing pattern in water also. The dissolution profiles of Aten-4 and Aten-2 in pH 1.2 is rapid and good, only Aten -3 failed to cross the similarity factor but $\mathrm{f}_{1}$ is within limit. In $\mathrm{pH} 4.5$ and 6.8 all brands fulfilled biowaiver requirements, except Aten-2 in $\mathrm{pH} 6.8$ that may be due to manufacturing process difference. In the same time Aten- 2 has $\mathrm{f}_{1}$ value 12 that is within the limit. Therefore, generic drugs with differing in vitro dissolution will not necessarily exhibit different in vivo performance. The results suggest that the formulation and/or the manufacturing process affect the dissolution and thus the bioavailability of the drug products. Thus the significance of the observed in-vitro differences must be confirmed by an in-vivo bioequivalence study.
\end{abstract}

Keywords: Atenolol; Dissolution testing; Quality control; Similarity factor $\mathrm{F}_{2}$; Difference factor $\left(\mathrm{F}_{1}\right)$; Biowaiver

\section{Introduction}

The speed of drug introduction to the marketplace is dependent upon its development processes and clinical estimation. The bioavailability and bioequivalence studies of drugs cost up to $\$ 250,000$ to $\$ 300,000$ each and can require up to 12 months to complete. On the other hand, in vitro tests are relatively inexpensive $(\$ 2,000)$ and fast. Dissolution studies and $\mathrm{f}_{2}$ profile calculations provide a significant economic support to a drug for its fast unveiling in the market at low rate.

FDA guideline permits waiver of in vivo bioavailability and bioequivalence studies on the basis of Biopharmaceutics Classification System (BCS). The BCS represents the framework for predicting the intestinal drug absorption based on its solubility and intestinal permeability. Recent research indicates that in vitro tests (Dissolution) can be used to waive additional in vivo bioequivalence studies for some pharmaceutical products and can also be used as cost-saving tool in approval of generic drugs.

The life expectancy at birth in the UAE population is 78.5 years [1]. Cardiovascular disease is the principal cause of death in the UAE, constituting $28 \%$ of total deaths [2]. Atenolol is a cardio selective $\beta$-blocker, widely used in the management of hypertension, angina pectoris, cardiac arrhythmias, and myocardial infarction [3].

The Biopharmaceutical characteristic of atenolol is described as sparingly to slightly soluble in water in different Pharmacopoeias $[4,5]$. Solubility of atenolol was evaluated in $\mathrm{pH}$ values (1.0-7.5 or 1.2-6.8) that vary from 24.8 to $31.3 \mathrm{mg} / \mathrm{mL}$ [6]. This indicates that the solubility of atenolol is $\mathrm{pH}$ dependent.

On the basis of studied biopharmaceutical data, atenolol could be clearly classified into BCS Class III. In addition, atenolol is listed in WHO Model List of Essential Medicines [7]. According to WHO Technical Report, atenolol in vitro equivalence may be evaluated under Biowaiver conditions for BCS Class III [8].

The aim of this study was to investigate the influence of experimental conditions on atenolol release from different immediate-release tablet formulations (available in Ras $\mathrm{Al}$ Khaimah market) by establishing the bioequivalence and to clarify about biowaiver application on drug by using dissolution profile that should be similar in three different $\mathrm{pH}$ media i.e., $\mathrm{pH} 1.2,4.5$, and 6.8 .

This approach is meant to reduce unnecessary in vivo bioequivalence studies however, is restricted to non-critical drug substances in terms of solubility, permeability, and therapeutic range, and to non-critical pharmaceutical forms. Biowaivers are generally provided for multiple strengths and generic brands (manufactured by different pharmaceutical companies) after approval of a bioequivalence [9].

\section{Materials and Methods}

\section{Instruments}

Analysis of Atenolol was carried out on UV -Vis Spectrophotometer (Shimadzu UV 1800, Tokyo Japan), Electronic balance (Mettler Toledo, England), hardness tester (Tab Machines), pH meter (Hanna), disintegration (Veego VTD-D USP) and Tablet Dissolution Appartus (Veego-VD-6D, USP).

\section{Materials and reagents}

Reference Atenolol was a kind gift sample from Julphar Pharmaceutical.

*Corresponding author: Shahnaz Usman, Associate Professor, Department of Pharmaceutics, RAK College of Pharmaceutical Sciences, RAKMHSU Ras Al Khaimah, UAE, Tel: +971 558902559; Fax: +971 72269997; E-mail: shahnaz.usman@rakmhsu.ac.ae, shahnazgauhar@gmail.com

Received October 24, 2013; Accepted January 09, 2014; Published January 13 2014

Citation: Usman S, Alam A, Nadeem N, Khawar R, Intesar Z (2014) Biowaiver Studies of Atenolol Tablets (100mg) - An Alternative to In Vivo Bioequivalence Studies. Nat Prod Chem Res 2: 125 doi:10.4172/ 2329-6836.1000125

Copyright: $\odot 2014$ Usman S, et al. This is an open-access article distributed under the terms of the Creative Commons Attribution License, which permits unrestricted use, distribution, and reproduction in any medium, provided the original author and source are credited. 
Different brands of Atenolol tablets (100 mg) were purchased from randomly selected pharmacies in UAE. Distilled water was prepared freshly to prepare following dissolution medium.

1. Buffer $\mathrm{pH} 1.2$, SGF without enzymes or $0.1 \mathrm{~N} \mathrm{HCl}$;

2. Buffer $\mathrm{pH} 4.5$;

3. Buffer pH 6.8 or SIF without enzymes

\section{Spectrophotometric condition}

Base line was adjusted to zero by using blank solvent respectively for different medium. Standard and test sample were analyzed.

\section{Physiochemical parameters}

Before performing the dissolution of drug in different dissolution medium it is important to analyze physiochemical properties of the finished product. Any deviation from the physical parameters can lead to marked difference in the dissolution profiles. Assessments of physicochemical parameters were done which included uniformity of weight, hardness, diameter, thickness, disintegration test and assay content $[10,11]$.

\section{Dissolution study}

After the establishment of BCS classification dissolution has been used as a qualitative tool that provides measurement of the bioavailability of a drug as well as demonstration of bioequivalence. It is also a reliable in-vitro predictor of bioavailability.

The dissolution profile of atenolol tablets was assessed in $900 \mathrm{ml}$ of buffer $\mathrm{pH}$ 1.2, 4.5 and 6.8 using US Pharmacopoeia dissolution apparatus II [10]. Before running in specified medium it was also run in distilled water (general dissolution medium)

\section{Preparation of reagents}

1) $\mathrm{pH}$ 1.2: $8.5 \mathrm{ml}$ of $\mathrm{HCl}$ and dissolve in $1000 \mathrm{ml}$ of distilled water [10].

2) $\mathrm{pH}$ 4.5: $6.8 \mathrm{~g}$ of Potassium dihydrogen phosphate and dissolve in $1000 \mathrm{ml}$ of distilled water [10].

3) $\mathrm{pH}$ 6.8: Potassium Phosphate, Monobasic, (0.2 M). Dissolve 27.22 $\mathrm{g}$ of Monobasic Potassium Phosphate $\left(\mathrm{KH}_{2} \mathrm{PO}_{4}\right)$ in water, and dilute with water to $1000 \mathrm{ml}$.

Take $250 \mathrm{ml}$ of $0.2 \mathrm{M}$ Monobasic potassium phosphate solution and $112 \mathrm{ml}$ of $0.2 \mathrm{M} \mathrm{NaOH}$ solution and make up the volume up to $1000 \mathrm{ml}$ with distilled water [12].

\section{Dissolution procedure}

- The temperature and degree of agitation were set at $37^{\circ} \mathrm{C} \pm 0.5$ and $50 \mathrm{rpm}$ respectively.

- $10 \mathrm{ml}$ Samples were collected at predetermined time intervals $5,10,15,30,45,60$ and 70 minutes and filtered (Millipore) to remove any insoluble excipients.
- $10 \mathrm{ml}$ of fresh medium already equilibrated to $37^{\circ} \mathrm{C}$ was replaced into dissolution medium after each sampling in order to maintain sink condition.

- Six tablets per brand were used for the study.

- The filtered samples were analyzed by the Ultra-violet spectrophotometric method (UV) at $294 \mathrm{~nm}$ wavelength.

- The concentration and the percentage release in each time interval was determined.

\section{Standard preparation}

Weigh accurately and dissolve $50 \mathrm{mg}$ of atenolol (reference standard) in $100 \mathrm{ml}$ of mediums ( $\mathrm{pH}=1.2,4.5$, and 6.8 separately). Pipette out $2 \mathrm{ml}$ from stock solution and dilute up to $100 \mathrm{ml}$ with respective medium to obtain final concentration of $10 \mu \mathrm{g} / \mathrm{ml}$.

\section{Data analysis}

The uniformity of weight, disintegration and content uniformity were analyzed with simple statistics - percentage deviation while differences in the in vitro dissolution profiles were evaluated using the model-independent approach based on the similarity factor $\left(f_{2}\right)$ and difference factor $\left(f_{1}\right)$ as follows:

\section{Similarity factor was calculated by using formula}

$$
\mathrm{f}_{2}=50^{*} \log \left\{\left[1+(1 / \mathrm{n}) \sum \mathrm{t}=\ln \left(\mathrm{R}_{\mathrm{t}}-\mathrm{T}_{\mathrm{t}}\right)^{2}\right]^{-0.5 *} 100\right\}
$$

Where $R_{t}$ and $T_{t}$ are percent dissolved at each time point for reference and test respectively. Values of 50 or above (50-100) ensure similarity of the curves.

Difference factor $\left(\mathbf{f}_{1}\right)$ : Difference factor can be mathematically computed by using

$$
\mathrm{f}_{1}=\left\{\left[\mathrm{S}_{\mathrm{t}=1}{ }^{\mathrm{n}}\left|\mathrm{R}_{\mathrm{t}}-\mathrm{T}_{\mathrm{t}}\right|\right] /\left[\mathrm{S}_{\mathrm{t}=1}{ }^{\mathrm{n}} \mathrm{R}_{\mathrm{t}}\right]\right\} \times 100
$$

Difference factor of 0-15 ensures minor difference between two products [13].

\section{Results}

The generic brands that were used in this study had a significant variation in their prices (The lowest price is AED 20.5 and the highest one is AED 60) whereas the active ingredient as well as the excipient used should fulfill the specification of USP/BP.

\section{Physicochemical tests}

All the formulations confirmed to USP-32 regulations on Pharmacopeial tests (Table 1).

\section{Comparison of dissolution profiles}

Figures 1-4 and Table 2 represent the dissolution profiles comparison and corresponding data of the four formulations in dissolution medium, $\mathrm{pH} \mathrm{1.2,} 4.5$ and 6.8. Table 2 shows the statistical result for similarity factor, $\mathrm{f}_{2}$ and difference factor, $\mathrm{f}_{1}$ using innovator

\begin{tabular}{|c|c|c|c|c|c|c|}
\hline Brands & Uniformity of Weight & Thickness & Diameter & Hardness & Disintegration & Content Assay \\
\hline & $\mathrm{mg}$ & $\mathrm{mm}$ & $\mathrm{mm}$ & $\mathrm{kg} / \mathrm{cm} 2$ & $\min$ & $\%$ \\
\hline Aten-1 & $434.3 \pm 1.02$ & $5.8 \pm 0.03$ & $10.8 \pm 0.03$ & $7.5 \pm 1.0$ & $4.59 \pm 0.56$ & $99.65 \pm 2.1$ \\
\hline Aten-2 & $339 \pm 1.23$ & $5.3 \pm 0.011$ & $10 \pm 0.01$ & $3.1 \pm 1.03$ & $2.5 \pm 1.01$ & $103.1 \pm 0.99$ \\
\hline Aten-3 & $415 \pm 1.48$ & $4.6 \pm 0.05$ & $10.6 \pm 0.04$ & $6.5 \pm 0.65$ & $5.53 \pm 1.24$ & $101.31 \pm 1.75$ \\
\hline Aten-4 & $394.5 \pm 0.89$ & $5.5 \pm 0.02$ & $9.8 \pm 0.03$ & $7.5 \pm 0.87$ & $6.0 \pm 0.98$ & $100.56 \pm 1.32$ \\
\hline
\end{tabular}
product as the reference.

Table 1: Physicochemical properties of 4 different brands of Atenolol $100 \mathrm{mg}$ tablets. 


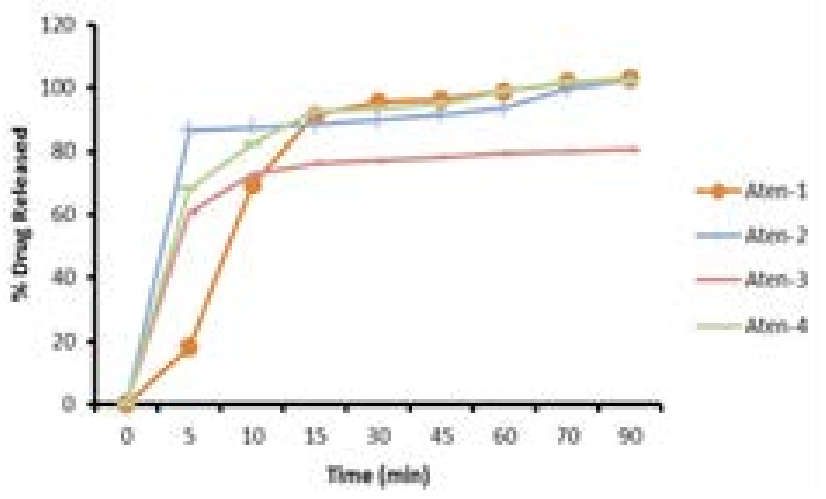

Figure 1: Dissolution Profile in Distill water.

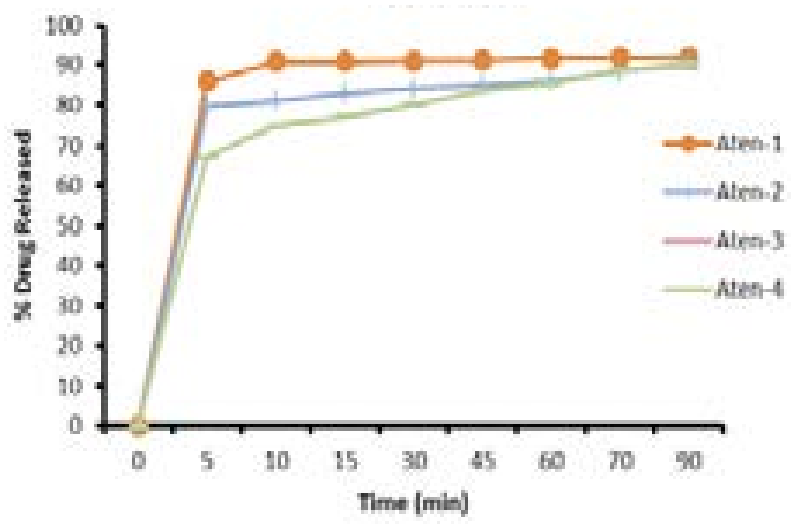

Figure 2: Dissolution Profile at $\mathrm{pH} 1.2$ Buffer solution.

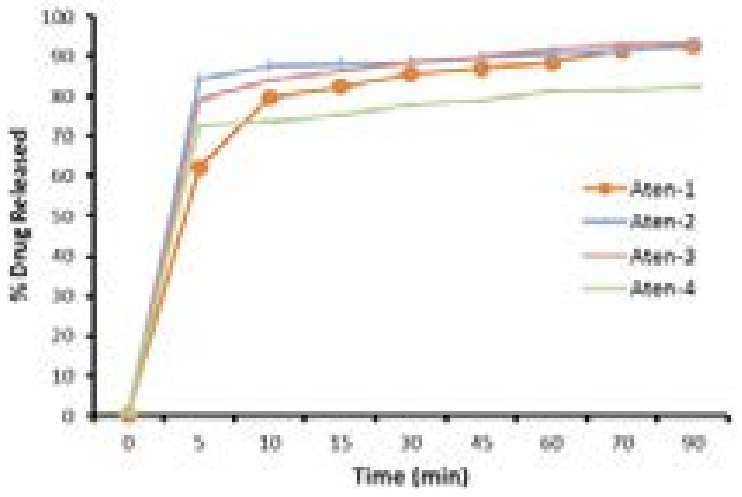

Figure 3: Dissolution Profile at $\mathrm{pH} 4.5$ Buffer solution.

\section{Discussion}

Hypertension is a widely prevalent and is the leading risk factor for the development of cardiovascular disease (CVD). This post marketing surveillance study aimed to collect information on the efficacy, safety and interchangeability of atenolol tablets because more than 10 different brands of atenolol are present in the Ras Al Khaimah local market, coming from different sources (manufacturer).

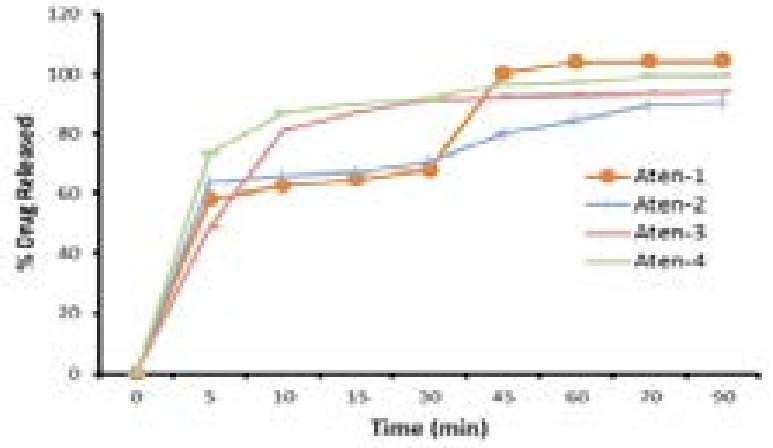

Figure 4: Dissolution Profile at pH 6.8 Buffer solution.

In purposed study dissolution test was carried out in four different medium to establish bioequivalence among the different brands. The primary goal of dissolution testing is to use as a qualitative tool to provide measurement of the bioavailability of a drug. Generic drugs are copies of innovator drug products. So they are promoted for use in practice because they are usually less expensive than the innovator products, thereby improving access to life-saving drugs, especially in developing countries.

In case of present study four different brands of Atenolol tablets (100 $\mathrm{mg}$ ) immediate release has been studied for their bioequivalence studies. First the dissolution was run in distilled water (Figure 1) because under the normal circumstances, the dissolution testing should be conducted at $37^{\circ} \mathrm{C}$ in distilled water then noted into different dissolution mediums ( $\mathrm{pH} 1.2,4.5,6.8$ ) to cover the whole GIT environment of different $\mathrm{pH}$ (Figures 2- 4). The FDA recommended dissolution medium for atenolol is $0.1 \mathrm{~N} \mathrm{HCl}$. Because it is not freely soluble in water but Figure 1 shows a good releasing pattern of atenolol in water also.

Similarity factor $\left(\mathrm{f}_{2}\right)$ and difference factor, $\mathrm{f}_{1}$ is a simple and viable comparison approach to assess bioequivalent between two formulations. According to FDA (2000) [14], a drug product is considered to be very rapidly released if $\geq 85 \%$ of the drug is dissolved in 15 minute, which corresponds to gastric emptying half-life (T50\%) in fasting conditions.

The factor $\mathrm{f}_{1}$ is proportional to the average difference between the two profiles, whereas factor $f_{2}$ is inversely proportional to the average squared difference between the two profiles, with emphasis on the larger difference among all the time-points. The factor $\mathrm{f}_{2}$ measures the closeness between the two profiles [15].

In present study, all of the four brands show the fulfillment of the compendial specification for uniformity of weight, hardness, disintegration and content assay (Table 1). All the brands are within their expiry dates but there is major difference in price that varies between 60 AED to 20.5 AED. Regardless of price, generic products should be compared with innovator for its quality and efficacy. The objective of the present study was to compare the quality among different brands of same active ingredient as well to examine the possibility of waiver for in vivo bioequivalence study.

Figures 2-4 and Table 2 show the dissolution profiles of tablets in $0.1 \mathrm{~N} \mathrm{HCl}(\mathrm{pH} 1.2)$. Aten- 4 shows very rapid dissolution, $86.03 \%$ in 15 minutes whereas Aten- 2 have $\mathrm{f}_{2}=59.33$ with innovator. Only Aten -3 failed to cross the similarity factor. Whereas on the other hand the release patterns of all the four brands are supposed to be same because of $\mathrm{f}_{1}$ that is within limit (0-15). 
Citation: Usman S, Alam A, Nadeem N, Khawar R, Intesar Z (2013) Biowaiver Studies of Atenolol Tablets (100mg) - An Alternative to In Vivo Bioequivalence Studies. Nat Prod Chem Res 2: 125 doi:10.4172/ 2329-6836.1000125

Page 4 of 5

\begin{tabular}{|c|c|c|c|c|c|}
\hline Medium & Time & Aten-1 $\%$ Released \pm SD & Aten-2 $\%$ Released \pm SD & Aten-3 $\%$ Released \pm SD & Aten-4 $\%$ Released \pm SD \\
\hline \multirow[t]{8}{*}{ pH 1.2} & 5 & $85.939 \pm 1.06$ & $79.59 \pm 3.59$ & $67.09 \pm 8.00$ & $84.202 \pm 1.09$ \\
\hline & 10 & $90.895 \pm 2.32$ & $81.006 \pm 3.27$ & $75.04 \pm 5.22$ & $85.597 \pm .74$ \\
\hline & 15 & $90.8354 \pm 2.31$ & $82.896 \pm 2.85$ & $77.202 \pm 4.26$ & $86.0286 \pm 1.17$ \\
\hline & 30 & $91.0808 \pm 2.25$ & $84.12 \pm 3.62$ & $80.166 \pm 3.27$ & $85.9878 \pm 1.54$ \\
\hline & 45 & $91.2436 \pm 2.05$ & $85.068 \pm 3.47$ & $83.68 \pm 2.36$ & $87.0905 \pm 1.21$ \\
\hline & 60 & $91.65 \pm 1.88$ & $86.208 \pm 3.67$ & $85.418 \pm 2.05$ & $87.7684 \pm 1.06$ \\
\hline & 70 & $91.8982 \pm 1.68$ & $88.44 \pm 5.82$ & $88.752 \pm 1.86$ & $88.1112 \pm 1.13$ \\
\hline & 90 & $92.108 \pm 1.58$ & $90.86 \pm 6.73$ & $89.76 \pm 1.45$ & $88.2776 \pm 1.25$ \\
\hline F2 & & Innovator & 59.33 & 47.27 & \\
\hline F1 & & Innovator & 7 & 11 & 4 \\
\hline \multirow[t]{8}{*}{$\mathrm{pH} 4.5$} & 5 & $61.99 \pm 12.55$ & $84.216 \pm 4.24$ & $79.272 \pm 2.79$ & $72.796 \pm 1.01$ \\
\hline & 10 & $79.696 \pm 2.66$ & $87.528 \pm 1.02$ & $84.078 \pm 2.80$ & $73.55 \pm 1.26$ \\
\hline & 15 & $82.382 \pm 1.49$ & $87.962 \pm 0.80$ & $86.288 \pm 1.62$ & $75.422 \pm 1.29$ \\
\hline & 30 & $85.582 \pm 2.30$ & $88.382 \pm 1.19$ & $88.62 \pm 1.37$ & $77.752 \pm 1.90$ \\
\hline & 45 & $87.01 \pm 2.12$ & $89.474 \pm 0.91$ & $89.862 \pm 1.02$ & $79.002 \pm 1.85$ \\
\hline & 60 & $88.502 \pm 0.92$ & $90.47 \pm 1.04$ & $91.788 \pm 1.38$ & $81.304 \pm 1.86$ \\
\hline & 70 & $91.436 \pm 2.26$ & $91.222 \pm 1.12$ & $92.646 \pm 1.46$ & $81.662 \pm 2.11$ \\
\hline & 90 & $92.34 \pm 1.45$ & $92.466 \pm 1.28$ & $93.154 \pm 1.73$ & $82.28 \pm 2.42$ \\
\hline F2 & & Innovator & & & 53.4 \\
\hline F1 & & Innovator & 6 & 5 & 10 \\
\hline \multirow[t]{8}{*}{$\mathrm{pH} 6.8$} & 5 & $58.054 \pm 3.80$ & $63.552 \pm 3.64$ & $48.744 \pm 7.39$ & $73.482 \pm 3.66$ \\
\hline & 10 & $62.5092 \pm 2.08$ & $65.872 \pm 1.72$ & $81.144 \pm 9.12$ & $86.89 \pm 4.00$ \\
\hline & 15 & $64.6526 \pm 2.36$ & $67.02 \pm 1.50$ & $87.102 \pm 5.33$ & $90 \pm 3.58$ \\
\hline & 30 & $68.0234 \pm 4.06$ & $70.46 \pm 2.94$ & $91.234 \pm 1.41$ & $91.682 \pm 2.94$ \\
\hline & 45 & $100.22 \pm 5.75$ & $79.918 \pm 7.78$ & $92.236 \pm 1.39$ & $96.35 \pm 2.13$ \\
\hline & 60 & $103.92 \pm 0.82$ & $84.508 \pm 7.46$ & $92.754 \pm 1.25$ & $97.25 \pm 1.72$ \\
\hline & 70 & $104.15 \pm 0.89$ & $89.422 \pm 2.63$ & $93.286 \pm 1.39$ & $99.32 \pm 1.50$ \\
\hline & 90 & $104.34 \pm 0.87$ & $90.298 \pm 2.37$ & $93.65 \pm 1.67$ & $99.45 \pm 1.45$ \\
\hline F2 & & Innovator & 45.02 & & \\
\hline F1 & & innovator & 12 & 17 & 16 \\
\hline
\end{tabular}

Table 2: Dissolution data of four brands of Atenolol $(100 \mathrm{mg})$ tablets with $\mathrm{f}_{2}$ comparison.

In $\mathrm{pH} 4.5$ and 6.8 all brands may be considered as very rapidly dissolving, as more than $85 \%$ of the labeled amounts of the drug substance dissolve within 15 minutes, except Aten- 4 in pH 4.5 but it crossed the $\mathrm{f}_{2}$ and aten- 2 after 90 minutes dissolved $90.3 \%$ in $\mathrm{pH} 6.8$ but $\mathrm{f}_{2}$ is 45 that may be due to manufacturing process difference (Table 2). In the same time Aten-2 has $\mathrm{f}_{1}$ value within the limit that is 12 but Aten3 and 4 are not fulfilling the $f_{1}$ requirement. It indicated that the release of drugs from dosage form is influenced by different factors. Therefore, generic drugs with differing in vitro dissolution will not necessarily exhibit different in vivo performance.

The $f_{2}$ calculation was applied to test the dissolution profile similarity for these products to ascertain equivalency. The $\mathrm{f}_{2}$ values for all generic samples tested were not $\geq 50$ in all three media, suggesting that these products are not similar to the innovator product. The generic drugs assessed were pharmaceutically equivalent to the innovator products but were not qualified for Biowaiver. According to the WHO biowaiver testing procedure, a biowaiver can be considered for BCS Class 3 drugs that are very rapidly dissolving ( $85 \%$ in $15 \mathrm{~min}$ ).

Therefore, to use in vitro dissolution as a surrogate for bioequivalence studies for regulatory purposes, manufacturers of generic products need to consider factors that affect solubility and permeability of their products when formulating them. So under a conservative conclusion, if a drug product undergoes $85 \%$ dissolution in 15 minutes under mild dissolution test conditions, generally, then it should not have any bioavailability problems.

Previous researches in this area have shown that the post-marketing evaluation of drug products is important to develop the confidence for manufacturer in order to ensure the safety and efficacy of the product
[16-24]. As well as this kind of studies help the healthcare people in interpretation between different brands of same generic.

\section{Conclusion}

The post-market monitoring is very crucial for effective clinical outcome. The biowaiver study has emphasized that pharmaceutical equivalence indicated that the products have same drug molecules with approximately same pattern of dissolution release profile. On the bases of this in-vitro profile we can evaluate the therapeutic level of the drug in vivo. By making fine tunings in the bioequivalence study we can reduce the time, cost and unnecessary exposure of healthy subjects to medicines and finally to market the quality generic drug products.

\section{Acknowledgement}

The authors would like to thank RAK college of Pharmaceutical Sciences, RAK Medical and Health Sciences University, Ras AI Khaimah, UAE for continuous encouragement and support

\section{References}

1. Average life expectancy in UAE rises to 75 years.

2. (2006) Proposal to waive in vivo bioequivalence requirements for WHO Mode List of Essential Medicines immediate-release, solid oral dosage forms. WHO Expert Committee on Specifications for Pharmaceutical Preparations. WHO Technical Report Series, No. 937, Annex 7; World Health Organization: Geneva, Switzerland

3. Sweetman SC (2007) Martindale: The Complete Drug Reference. (35th Edn) Royal Pharmaceutical Society, Pharmaceutical Press, London, UK.

4. 2006, United States Pharmacopeia and National Formulary USP 30-NF 25 United Pharmacopeial Convention, Inc Rockville, MD. 
Citation: Usman S, Alam A, Nadeem N, Khawar R, Intesar Z (2013) Biowaiver Studies of Atenolol Tablets (100mg) - An Alternative to In Vivo Bioequivalence Studies. Nat Prod Chem Res 2: 125 doi:10.4172/ 2329-6836.1000125

5. Sesardic D, Prior C, Daas A, Buchheit $\mathrm{KH}$; National Institute for Biological Standards and Control, Hertfordshire, (2003) Collaborative study for establishment of the European Pharmacopoeia BRP batch 1 for diphtheria toxin. Pharmeuropa Bio 2003: 5-21.

6. Vogelpoel H, Welink J, Amidon GL, Junginger HE, Midha KK, et al. (2004) Biowaiver monographs for immediate release solid oral dosage forms based on biopharmaceutics classification system (BCS) literature data: Verapamil hydrochloride, propranolol hydrochloride, and atenolol. J Pharm Sci 93: 1945 - 1956.

7. Essential Medicines WHO Model List (EML) (15th edn) World Health Organization (WHO).

8. (2006) WHO Expert Committee on Specifications for Pharmaceutical Preparations.

9. (1999) Draft Guidance For Industry, Waiver of In Vivo Bioavailability and Bioequivalence Studies For Immediate Release Solid Oral Dosage Forms Containing Certain Active Moieties/Active Ingredients Based on a Biopharmaceutics Classification System. United States, Food and Drug Administration (FDA)/CDER.

10. (2007) United States Pharmacopeia and National Formulary USP 32-NF 27 The United States Pharmacopeial Convention, Inc. Rockville, MD, 1737.

11. (2002) British Pharmacopoea Appendix: XII, Disintegration of tablets and capsules. Royal Publishers: London, H A2-53.

12. (2004) The United States Pharmacopeia 27. The United States Pharmacopeia Convention, Rockville, MD, USA. 2011-2012.

13. (1997) Guidance for Industry: Dissolution testing of immediate-release solid oral dosage forms. U.S Department of Health and Human Services, Food and Drug Administration, Center for Drug Evaluation and Research (CDER), U.S. Government Printing Office: Washington, DC.

14. (2003) Guidance for industry: bioavailability and bioequivalence studies for orally administered drug products-general considerations. Rockville, MD: US Department of Health and Human Services, Food and Drug Administration (FDA), Center for Drug Evaluation and Research.
15. Shah VP, Tsong Y, Sathe P, Liu JP (1998) In vitro dissolution profile comparison-statistics and analysis of the similarity factor, f2. Pharm Res 15: 889-896.

16. Samar AA, Shaimaa A (2012) A Comparative study for evaluation of differen brands of Metformin Hydrochloride 500 mg tablets Marketed in Saudi Arabia. Life Science Journal 9: 4260-4266

17. Raheela B, Shahnaz G, Syed BSN, Shoukat M (2011) Pharmaceutical evaluation of different Brands of Levofloxacin Tablets $(250 \mathrm{mg})$ available in Local market of Karachi (Pakistan). Int J Curr Pharm Res 3: 15-22.

18. Anand KK, Amareshwara P (2012) Quality evaluation and comparative study on tablet formulations of different pharmaceutical companies. J Curr Chem Pharm Sc 2: 24-31.

19. Akinleye MO, Adelaja IA, Odulaja JO (2012) Comparative Evaluation of Physicochemical Properties of Some commercially available Brands of Metformin $\mathrm{Hcl}$ tablets in Lagos, Nigeria. Journal of Applied Pharmaceutical Science 2: 41-44.

20. Pamula RB, Surender G, Subhaskar Reddy KV, Ujwala P, Jyosthna G, et al (2010) Comparative in vitro evaluation of commercial metformin $\mathrm{HCl}$ tablets. JITPS 1:152-157.

21. Shah SU, Shah KU, Rehman A, Khan GM (2011) Investigating the in vitro drug release kinetics from controlled release diclofenac potassium-ethocel matrix tablets and the influence of co-excipients on drug release patterns. Pak Pharm Sci 24: 183-192.

22. Ashour S, Al-Khalil R (2005) Simple extractive colorimetric determination of levofloxacin by acid-dye complexation methods in pharmaceutical preparations. Farmaco 60: 771-775.

23. Alvarez-Lerma F, Palomar M, Olaechea P, León C, Sánchez M, et al. (2004) [Observational study investigating the use of levofloxacin in ICU patients] Enferm Infecc Microbiol Clin 22: 220-226.

24. Bundrick W, Heron SP, Ray P, Schiff WM, Tennenberg AM, et al. (2003) Levofloxacin versus ciprofloxacin in the treatment of chronic bacterial prostatitis: a randomized double-blind multicenter study. Urology 62: 537-541. 